\title{
$\begin{array}{r}\text { WAGENINGEN } \\ \text { UNIVERSITY \& RESEARCH } \\ \hline\end{array}$
}

\section{Oral processing behavior and dynamic sensory perception of composite foods: Toppings assist saliva in bolus formation}

van Eck, A., Hardeman, N., Karatza, N., Fogliano, V., Scholten, E., \& Stieger, $\mathrm{M}$.

This is a "Post-Print" accepted manuscript, which has been published in "Food Quality and Preference"

This version is distributed under a non-commercial no derivatives Creative Commons (a) (1) $\Theta \Theta$ reproduction in any medium, provided the original work is properly cited and not used for commercial purposes. Further, the restriction applies that if you remix, transform, or build upon the material, you may not distribute the modified material.

Please cite this publication as follows:

van Eck, A., Hardeman, N., Karatza, N., Fogliano, V., Scholten, E., \& Stieger, M. (2018). Oral processing behavior and dynamic sensory perception of composite foods: Toppings assist saliva in bolus formation. Food Quality and Preference. DOI: 10.1016/j.foodqual.2018.05.009

You can download the published version at:

https://doi.org/10.1016/j.foodqual.2018.05.009 


\section{Oral processing behavior and dynamic sensory perception of}

2 composite foods: Toppings assist saliva in bolus formation

3 Arianne van Eck ${ }^{\mathrm{ab}}$, Niels Hardeman ${ }^{\mathrm{b}}$, Niki Karatza $^{\mathrm{b}}$, Vincenzo Fogliano ${ }^{\mathrm{ab}}$, Elke Scholten ${ }^{\mathrm{ac}}$,

4 Markus Stieger ${ }^{a b^{*}}$

5

$6 \quad{ }^{a}$ TI Food and Nutrition, P.O. Box 557, 6700 AN Wageningen, The Netherlands

$7 \quad{ }^{\mathrm{b}}$ Food Quality and Design, Wageningen University, P.O. Box 17, 6700 AA Wageningen, The

8 Netherlands

$9{ }^{\mathrm{c}}$ Physics and Physical Chemistry of Foods, Wageningen University, P.O. Box 17, 6700 AA

10 Wageningen, The Netherlands

11

$12 *$ Corresponding author.

13 E-mail address: markus.stieger@wur.nl

14 Full postal address: Wageningen University, Food Quality and Design, P.O. Box 17, 6700 AA

15 Wageningen, The Netherlands 


\section{Abstract}

17 Composite foods consist of combinations of single foods, such as bread with toppings. Single foods can differ considerably in their mechanical and sensory properties. This study aimed to investigate the effect of toppings on oral processing behavior and dynamic sensory perception of carrier foods when consumed as composite foods. Two carriers (bread, crackers) and three toppings (firm cheese, cheese spread, mayonnaise) were selected and six carrier-topping combinations were prepared. Mastication behavior, bolus properties (33, 66 and 100\% of total mastication time) and dynamic sensory perception were determined for single carriers and all carrier-topping combinations. Both carriers with cheese spread and mayonnaise were chewed shorter and with fewer chews than single bread and crackers, although twice the mass of food was consumed. These toppings contributed to a faster bolus formation by providing moisture, so that less saliva was incorporated into the bolus during mastication. As a result of the moisture incorporation, carrier boli with toppings were softened and perceived less firm and less dry than carrier boli alone. The largest effects of toppings on oral processing behavior and perception were found for liquid-like mayonnaise, and these effects were more pronounced in dry crackers than in moist bread. We conclude that toppings assist saliva in bolus formation of carriers. Carriers drive oral processing behavior and texture perception whereas toppings drive overall flavor perception. This knowledge contributes to food design tailored for specific consumer segments and future personalized nutrition.

Keywords: composite foods, carrier foods, toppings, oral processing, bolus properties, sensory perception

\section{Highlights}

- Oral processing behavior and texture perception were driven by carriers

- Carriers with cheese spread and mayonnaise were chewed shorter than carriers alone

- Cheese spread and mayonnaise facilitated bolus formation of bread and crackers

- Less saliva was incorporated into bolus of carriers after addition of toppings 


\section{Introduction}

43 Many foods that are frequently consumed are composed of combinations of multiple single foods such as bread with cheese, crackers with spreads or yogurt with cereals. Throughout this paper, the term composite foods will refer to foods that are composed of two single foods. The single foods can differ considerably in composition, mechanical properties and sensory characteristics (Scholten, 2017; Szczesniak \& Kahn, 1984).

Oral processing behavior of composite foods is different from that of single foods. From the start of consumption, two single foods are mixed in the mouth, which results in complex oral processing behavior depending on the properties of both food components. Few studies investigated the impact of composite foods on oral processing behavior. One of those studies was performed by Hutchings et al. (2011), who studied oral processing behavior of gelatin and chocolate matrices with embedded peanuts. They found that the mastication behavior (chewing duration, number of chews, chewing frequency) was influenced by the type of matrix, and this was not altered by the type of peanuts (dry or moist) embedded in the matrix. The matrix was shown to influence breakdown of the embedded peanuts, as obvious from a variation in peanut particles size distributions. Larsen, Tang, Ferguson, Morgenstern, and James (2015) found that the release of embedded inclusions from a gel matrix ensured differences in breakdown pathways. While these two studies focused on matrices with embedded components, Devezeaux de Lavergne et al. (2016) investigated bi-layer model gels displaying mechanical contrast by combining two gel layers with different mechanical properties. Oral processing behavior of such gels showed oral processing characteristics between that of the two separate layers indicating the importance of the properties of both gel layers present. However, hard gel layers were found to influence oral processing behavior slightly more than soft gel layers. Only one research group investigated mastication behavior of commercially available composite foods (Engelen, Fontijn-Tekamp, \& Van Der Bilt, 2005; Gavião, Engelen, \& Van Der Bilt, 2004). They investigated the effect of spreading butter on different carrier foods, such as bread, cake and toast. They found a significant difference in mastication behavior between carrier foods alone and carriers with butter. Addition of butter decreased the number of chewing cycles of the drier carriers, such as toast and cake, but not for the more moist bread (Engelen et al., 2005). The researchers hypothesized that butter facilitated the lubrication and bolus formation of carriers and thereby reducing the number of chewing cycles. However, no information is 
currently available on the mechanisms underlying bolus formation in such foods and its influence on mastication behavior.

Few studies have attempted to investigate the sensory perception of composite foods. Adding sauces to carrier foods (vegetables with gravy, salmon with culinary sauce) decreased the perceived intensity scores of such carrier foods (Meinert, Frøst, Bejerholm, \& Aaslyng, 2011; Paulsen, Ueland, Nilsen, Öström, \& Hersleth, 2012). In another study, the impact of different carriers (chicken broth, white rice and grilled chicken) on soy sauce perception was investigated (Cherdchu \& Chambers, 2014). They found that the carriers did not strongly affect the classification pattern of soy sauces, and differences between soy sauces were still observed. However, solid white rice and grilled chicken tended to modify the sensory properties of the soy sauce more than liquid chicken broth. In another study, dynamic texture perception was shown to increase in complexity (i.e. the number of dominant attributes increased) when model gel matrices contained two or more embedded inclusions (Tang, Larsen, Ferguson, \& James, 2017). In the case of model bi-layer gels, dynamic sensory perception corresponded to an average of the two single layers they were composed of (Devezeaux de Lavergne et al., 2016), while for breads with a crust, the harder crust dominated the dynamic texture perception (Gao, Ong, Henry, \& Zhou, 2017).

Oral processing behavior is relevant because it imparts structural changes to the food, thereby impacting dynamic sensory perception, oro-sensory exposure time, satiation and food intake (Campbell, Wagoner, \& Foegeding, 2016; Chen, 2009, 2015; Devezeaux de Lavergne, van de Velde, \& Stieger, 2017; Forde, 2018; Wang \& Chen, 2017). Oral processing behavior and dynamic sensory perception have been extensively studied for model foods and various single foods such as bread (Devezeaux de Lavergne et al., 2017; Gao et al., 2017; Jourdren et al., 2016; Koc, Vinyard, Essick, \& Foegeding, 2013; Le Bleis, Chaunier, Montigaud, \& Della Valle, 2016; Panouillé, Saint-Eve, Déléris, Le Bleis, \& Souchon, 2014; Witt \& Stokes, 2015), but little is known about oral processing behavior and sensory perception of composite foods, although these are often consumed. A multidisciplinary approach integrating food structure, oral processing behavior and dynamic sensory perception for composite foods may help to gain further understanding of how composite foods are perceived and which factors determine their perception. An understanding of the role of each single food may be used to control mastication behavior, bolus formation, sensory perception or liking of foods. Such insights are of relevance for food design tailored to specific consumer segments such as the increasing elderly population or people with decreased eating capabilities (Laguna \& Chen, 2016; Mosca \& Chen, 2016). 
106 In this study, carriers (bread and crackers) and toppings (firm cheese, cheese spread and 107 mayonnaise) were used as single foods, and they were combined into composite foods (carrier 108 with topping). The aim of this study was to investigate the effect of toppings on oral processing 109 behavior and dynamic sensory perception of these composite foods. Both carriers and toppings 110 are expected to influence the oral processing behavior and dynamic sensory perception, 111 however we hypothesize that carriers are the main determinant of oral processing behavior and 112 texture perception since they require oral breakdown before being swallowed safely. 


\section{Materials and Methods}

\section{$114 \quad 2.1 \quad$ Samples}

115 Carrier foods and toppings were combined to form composite foods. Two commercial carriers

116 were used, namely bread crumb (toast bread, Jacquet ${ }^{\circledR}$, France) and crackers (mini-toast naturel,

117 Haust $^{\circledR}$, The Netherlands), and three commercial toppings, namely firm cheese (AH Goudse 118 jong belegen, Albert Heijn, The Netherlands), cheese spread (Kiri ${ }^{\circledR}$ mit Sahne, BEL Group, 119 France) and low-fat mayonnaise (Licht en Romig, Calvé ${ }^{\circledR}$, Unilever, The Netherlands). These 120 foods were selected based on their similar fat content and difference in mechanical properties.

121 The carriers (2) were combined with the toppings (3) to create 6 combinations. The single 122 carriers and toppings ( 2 carriers and 3 toppings) were included as a reference, which gave a 123 total of 11 samples.

124 Table 1 presents an overview of the composition and product properties of the single foods.

125 The fat content was taken from the nutritional information on the product label. The moisture 126 content of the single foods was determined gravimetrically $\left(16-18 \mathrm{~h}\right.$ at $\left.105^{\circ} \mathrm{C}\right)$ in five 127 replicates. This method was also used for the expectorated boli, and is explained in more detail 128 in section 2.5.2. The water activity of the single foods was determined in three replicates using 129 a LabMaster aw (Novasina ${ }^{\circledR}$ ). The mechanical properties first peak force (associated to 130 firmness), adhesiveness and cohesiveness were determined in 9 replicates using two cycle 131 puncture tests with a Texture Analyzer (TA.XT Plus). This method was also used for the expectorated boli, and is explained in more detail in section 2.5.3.

133 The carriers were served at constant weight of $2.1 \mathrm{~g}$, which was based on the weight of the

134 single cracker. In addition, the dimensions of bread (35 x $35 \times 8 \mathrm{~mm})$ and crackers $(35 \times 35 \times$ $1358 \mathrm{~mm}$ ) were comparable. A feasibility test was performed with 6 consumers to quantify a natural 136 carrier-topping serving ratio. It was observed that consumers showed a natural eating behavior 137 when carriers and toppings were combined in a 1:1 weight ratio. All three toppings were 138 therefore also served at a constant weight of $2.1 \mathrm{~g}$. This gave a total weight of $4.2 \mathrm{~g}$ for carrier139 topping combinations (2.1 g carrier and $2.1 \mathrm{~g}$ topping). The toppings covered the carriers 140 completely. Carrier-topping combinations were prepared just before serving in order to prevent 141 moisture transfer from the toppings into the carriers. 


\subsection{Subjects}

48 healthy subjects were initially recruited, out of which 18 subjects ( 7 male and 11 female) were selected to participate $(25.6 \pm 2.93$ years, mean $\pm \mathrm{SD})$. Inclusion criteria were good dental health, no missing teeth and/or molars except wisdom teeth, no dental braces, no piercings in the mouth, no swallowing or mastication disorders and non-smoking habits. Only Caucasian adults were included in our study. Selection criteria assessed during the screening session were mechanically stimulated saliva flow rate, mastication time and liking of the carriers, toppings and composite foods. Subjects with low/high saliva flow rates (top and bottom 10\%), fast/slow mastication times (top and bottom 10\%) and who disliked the samples strongly (scores below 3 on 9 point hedonic scale) were excluded. Subjects gave written informed consent and received financial compensation for participation. The study protocol was submitted to the Medical Ethical Committee of Wageningen University (METC-WU) and exempted from ethical approval. All 18 subjects completed the study.

\subsection{Experimental approach}

Each subject attended 11 sessions of 45 minutes over a time period of three months. In the first two sessions, mastication behavior was characterized using video recordings. Subjects were instructed to chew each food as they would do naturally. These video recordings were used to determine the total mastication time for each sample by averaging the mastication times of all subjects and all replicates. Averaged total mastication times of bread without topping, with firm cheese, with cheese spread and with mayonnaise corresponded to $13.8 \pm 0.614 .2 \pm 0.613 .5 \pm 0.6$ and $11.7 \pm 0.5 \mathrm{~s}($ mean $\pm \mathrm{SE})$, respectively. Averaged total mastication times of cracker without topping, with firm cheese, with cheese spread and with mayonnaise corresponded to $20.9 \pm 0.6$ 21.1 $\pm 0.619 .6 \pm 0.5$ and $16.5 \pm 0.5 \mathrm{~s}($ mean $\pm \mathrm{SE})$, respectively. The third session was a training session, during which the sensory attributes and the procedures of the following sessions were introduced. Reference foods were used to acquaint the subjects with the different sensory attributes. The remaining eight sessions were used for bolus collection and sensory assessment.

During these sessions, subjects were asked to expectorate the bolus for each sample after time points corresponding to 33,66 and $100 \%$ of the averaged total mastication time using a stopwatch. In addition, subjects were asked to evaluate intensity of sensory attributes after one chew and at 33, 66 and $100 \%$ of total mastication time using progressive profiling method. Each method is explained in further detail in section 2.4 - 2.6.

For all sessions, samples were presented with three digit codes. Carriers and carrier-topping combinations were served on a plate, whereas the single toppings were served on a spoon. 
177 Subjects cleaned their palate after consumption of each sample with water and cucumber.

178 Cucumber was used as palate cleanser instead of commonly used crackers, since using one of the samples as palate cleanser was not preferred. Cucumber was chosen because it is a relatively bland tasting solid food with high moisture content by which it could aid in the removal of cracker/bread/topping residues.

\subsection{Characterization of mastication behavior using video recordings}

183 Oral processing behavior of all samples by $n=18$ subjects was characterized in triplicate using video recordings. Four stickers were placed on the subjects face, which were later used as reference points during the video analyses. Two stickers with a defined distance of $5 \mathrm{~cm}$ were placed on the forehead, one sticker was placed on the nose and one sticker was placed on the chin. Subjects were seated in a chair with a camera in front of them. They were asked to chew each food as they would do naturally, while being video recorded. The subjects were instructed to maintain their head straight to the camera, and not to block their mouth or face with their hand while eating. Furthermore, they were instructed to indicate the moment of swallowing by raising their hand.

192 The videos were analyzed using Kinovea software (version 0.8.15), which is a free software

193 that can be used to analyze mastication behavior. Each video was calibrated by setting the 194 distance between the two stickers on the forehead as $5 \mathrm{~cm}$. The path of the nose and chin sticker 195 was tracked by the software in order to determine the chewing movements. All videos were analyzed separately by two of the authors, after which they compared their findings until agreement on the start of consumption and the moment of swallowing was reached for each video.

The parameters collected from the videos included total mastication time (s), number of chews, chewing frequency (chews/s), maximum vertical jaw movement $(\mathrm{cm})$ and maximum lateral jaw movement $(\mathrm{cm})$. Total mastication time was defined as the time period between the moment when the lips were closed after placing the food in the mouth and the moment of swallowing. Subjects generally take multiple swallows during mastication, but only the moment of the main swallow was used for analysis. Chewing frequency was calculated by dividing the number of chews by the mastication time. Maximum vertical and lateral jaw movements were defined as the maximum distance between the nose and chin in vertical and lateral directions, respectively. In addition, parameters describing oral processing behavior were also analyzed for tertiles of 
mastication time (i.e. $0-33 \%, 33-66 \%$ and $66-100 \%$ of mastication time) in order to analyze 209 changes throughout mastication.

\subsection{Characterization of bolus properties throughout mastication}

211 Different bolus properties were analyzed at 33, 66 and 100\% of total mastication time 212 corresponding to early chew down, late chew down and the moment of swallowing, 213 respectively. Boli were collected from $\mathrm{n}=18$ subjects in quadruplicate; one replicate was 214 photographed for illustration purposes, one replicate was used to determine the moisture and saliva content of the boli and two replicates were used to determine the mechanical properties of the boli. Within each replicate, the sample serving order was randomized with respect to sample type and expectoration time point. One replicate was presented in two different sessions, so that half of the samples was analyzed in the first session and the other half in the second session. All boli were analyzed for the different properties immediately after expectoration.

\subsubsection{Images of expectorated boli}

Pictures of expectorated boli were taken for all time points and all samples. The boli were photographed on a grey background using a digital camera (Canon IXUS 180). The camera was placed in a tripod at a distance of $40 \mathrm{~cm}$ above the bolus. One image was obtained for each bolus. These pictures were taken in order to illustrate differences between samples at different time points. They were not used for further image analysis.

\subsubsection{Moisture and saliva content of expectorated boli}

Boli were collected in petri dishes covered with lids and analyzed within an hour after expectoration in order to prevent moisture evaporation from the samples. $2-3 \mathrm{~g}$ of the expectorated boli were placed on aluminum dishes, weighed and dried for $16-18 \mathrm{~h}$ at $105^{\circ} \mathrm{C}$ in an atmospheric oven (Venti-line, VWR®). After drying, samples were cooled in a desiccator for 30 min and subsequently weighed. Bolus moisture content (MC) on a wet weight basis was calculated using $M C=\left(m_{0}-m_{1}\right) / m_{0} \cdot 100 \%$, where $m_{0}$ is the weight of the sample before drying and $\mathrm{m}_{1}$ is the weight after drying. Bolus moisture content on a dry weight basis was calculated using $M C d b=\left(m_{0}-m_{1}\right) / m_{1}$, which was subsequently used to calculate the saliva content (SC) per gram dry food by subtracting the moisture content on a dry weight basis of the product from the moisture content on a dry weight basis of the bolus (MCdb). The rate of saliva incorporation ( $\mathrm{g} / \mathrm{min}$ ) was calculated by dividing the saliva content (SC) by mastication time. These calculations were based on the assumption that the bolus was fully expectorated. Few samples ( 8 out of 432 samples) resulted in slightly negative values for the 
saliva content, most likely due to small measurement errors. These samples were excluded from 241 the statistical analyses.

\subsubsection{Mechanical properties of expectorated boli}

243 The mechanical properties of the expectorated boli were analyzed in duplicate using two cycle 244 puncture tests with a Texture Analyzer (TA.XT Plus) fitted with a $500 \mathrm{~g}$ load cell. A cylindrical 245 probe with a flat surface and a diameter of $4 \mathrm{~mm}$ was used. Punctures were performed up to a 246 strain of $50 \%$ of the initial bolus height with a constant speed of $5 \mathrm{~mm} / \mathrm{s}$. The probe was then retrieved at the same speed of $5 \mathrm{~mm} / \mathrm{s}$ and a resting time of $5 \mathrm{~s}$ was applied before a second puncture was performed. Three measurements, each at a different location of one expectorated bolus, were performed to obtain an averaged value. The mechanical properties of expectorated mayonnaise samples were not analyzed since these samples could not been detected by the Texture Analyzer due to their liquid behavior.

252 First peak force (associated to firmness), adhesiveness and cohesiveness were determined from the force-time curves as described before by Devezeaux de Lavergne, van de Velde, van

254 Boekel, and Stieger (2015). First peak force was defined as the maximum peak force during the first puncture cycle. Adhesiveness was defined as the area under the negative force-time curve during the first cycle. Cohesiveness was defined as the ratio between the area under the (positive) force-time curve obtained during the second and first puncture cycle.

\subsection{Characterization of dynamic sensory perception using progressive profiling}

All samples were evaluated in duplicate for four sensory attributes (firmness, stickiness, dryness and flavor intensity) at four different moments of mastication (first chew, and 33, 66 and $100 \%$ of total mastication time) by $n=18$ subjects using progressive profiling. The attributes firmness (i.e. force required to push the tongue through the product to the upper palate), stickiness (i.e. degree to which the product adheres to any mouth surface while chewing) and dryness (i.e. dry and rough feeling on the tongue and oral cavity) were selected because they best describe the differences between the carriers and toppings and the expected changes thereof during oral processing. The attribute overall flavor intensity (i.e. the total amount of flavor) was included because the samples assessed differed strongly in flavor quality and to avoid dumping 268 effects.

269 Subjects were asked to evaluate the sensory attributes immediately after expectoration. An unstructured $100 \mathrm{~mm}$ line scale anchored from "not at all" to "extremely" was used (Eye 
272 design, so that 9 subjects started the sessions with the assessment of the attributes firmness and

273 stickiness and the other 9 subjects started with the attributes dryness and flavor intensity.

\section{$274 \quad 2.7 \quad$ Statistical data analyses}

275 Results were reported as mean values with standard error ( $\mathrm{n}=18$ subjects). Outliers (Z-

276 score $>3.29$ ) were removed from the data (typically less than $1.6 \%$ of all values). Data were

277 checked for normality, and a log transformation was applied for the parameters peak force and

278 adhesiveness in order to obtain normally distributed data. Linear mixed models were performed

279 for all mastication, bolus and sensory parameters for single carriers and all carrier-topping 280 combinations (lmerTest package)(RStudio, version 1.0.143). Significance level of $\mathrm{p}<0.05$ was 281 chosen. For the mastication parameters, carrier and topping were set as fixed effects, and 282 subject and replicate were set as random effects. For the bolus and sensory parameters, carrier, 283 topping and time were set as fixed effects, and subject and replicate were set as random effects. 284 Then, a model including only the bolus and sensory data at $100 \%$ of mastication was carried 285 out to study the differences in bolus and sensory properties between carriers with and without 286 toppings at the moment of swallowing. For this analysis, carrier and topping were set as fixed 287 effect, and subject and replicate were set as random effects. Interaction effects were included 288 in all models, and random effects that were not significant were excluded from all models. The 289 relationships between oral processing parameters throughout mastication of the different 290 carriers with and without toppings were summarized using Principal Component Analysis 291 (PCA) on subject averaged data (The Unscrambler X software, version 10.4.1). 


\section{Results}

\subsection{Characterization of mastication behavior}

294 For both carriers, mastication time and number of chews are summarized in Figure 1. 295 Significant carrier effects $(\mathrm{F}=638.4, \mathrm{p}<0.001 ; \mathrm{F}=584.9, \mathrm{p}<0.001)$, topping effects $(\mathrm{F}=44.0$, $296 \mathrm{p}<0.001 ; \mathrm{F}=26.9, \mathrm{p}<0.001)$ and carrier-topping interactions $(\mathrm{F}=4.0, \mathrm{p}=0.008 ; \mathrm{F}=3.6, \mathrm{p}=0.013)$ 297 were found for both mastication time and number of chews (Table 2), indicating that the effects 298 of toppings on carrier foods were not the same for bread and crackers. On average, crackers were processed longer in the mouth and with a higher number of chews compared to bread. For example, single crackers were masticated for $20.9 \pm 0.6$ s with $27.7 \pm 0.8$ chews, whereas single bread was masticated for $13.8 \pm 0.5 \mathrm{~s}$ with $17.8 \pm 0.8$ chews. Addition of mayonnaise to bread significantly decreased total mastication time from $13.8 \pm 0.5$ to $11.7 \pm 0.5 \mathrm{~s}(\mathrm{p}<0.05)$, whereas no significant effects were found for addition of firm cheese and cheese spread. In the case of crackers, both mayonnaise and cheese spread had a significant effect on mastication time ( $p<0.05$ ). The mastication time of crackers decreased from $20.9 \pm 0.6$ to $19.6 \pm 0.5 \mathrm{~s}$ for cheese spread and to $16.5 \pm 0.5 \mathrm{~s}$ for mayonnaise. Addition of firm cheese to crackers did not significantly affect the total mastication time $(21.1 \pm 0.6 \mathrm{~s})$. Similar results were found for the number of chews required until swallowing. Addition of mayonnaise significantly decreased the number of chews required to swallow both bread and crackers, and cheese spread significantly decreased the number of chews for crackers only. Firm cheese did not lead to changes in number of chews for neither carriers. On average, similar effects of toppings on oral processing behavior of carriers were found for bread and crackers, but the effects were larger in crackers than in bread.

$<$ Figure 1 about here>

Chewing frequencies of the carriers with and without toppings varied between $1.25 \pm 0.02$ and $1.36 \pm 0.03$ chews/s (data not shown). Even though these differences in chewing frequencies were small, significant carrier effects $(\mathrm{F}=10.9, \mathrm{p}=0.001)$ and topping effects $(\mathrm{F}=2.9, \mathrm{p}=0.034)$ were found.

Jaw movements were recorded during mastication, and maximum vertical and lateral jaw movements were determined (data not shown). A significant carrier effect was found for both maximum vertical jaw movements $(\mathrm{F}=16.4, \mathrm{p}<0.001)$ and maximum lateral jaw movements 
$324(\mathrm{~F}=12.7, \mathrm{p}<0.001)$. The results show that jaw movements in both directions were larger for 325 crackers than for bread. For example, the maximum vertical and lateral jaw movements of single bread were $19.7 \pm 0.6$ and $19.1 \pm 0.9 \mathrm{~mm}$, whereas this was $22.4 \pm 0.8$ and $20.3 \pm 0.7 \mathrm{~mm}$ for single crackers. In case toppings were added, larger maximum vertical jaw movements were observed $(\mathrm{F}=7.8, \mathrm{p}<0.001)$, but this effect was only significant after addition of firm cheese and cheese spread and not for mayonnaise. A significant topping effect was found for maximum lateral jaw movements $(\mathrm{F}=3.8, \mathrm{p}=0.011)$, but none of the toppings affected the lateral jaw movements of single carriers significantly.

Besides characterization of total mastication behavior, the mastication parameters were also analyzed for tertiles of mastication time, i.e. early chew down ( 0 - 33\% of total mastication time), middle chew down (33 - 66\% of total mastication time), and late chew down (66-100\% of total mastication time). Chewing frequency decreased towards the end of mastication. Averaged chewing frequency for all samples was $1.10 \pm 0.01$ chews/s during late chew down, which was lower than during the earlier stages of mastication $(1.28 \pm 0.01$ chews/s for early chew down, $1.32 \pm 0.01$ for middle chew down). In addition, maximum vertical jaw movements were largest during early chew down $(19.4 \pm 0.2 \mathrm{~mm})$, and decreased during middle and late chew down $(16.4 \pm 0.2$ and $16.4 \pm 0.2 \mathrm{~mm})$. No differences in maximum lateral jaw movements throughout mastication were observed.

$<$ Table 2 about here>

$<$ Table 3 about here>

\subsection{Characterization of bolus properties}

\subsubsection{Moisture content of boli and saliva incorporation}

348 Figure 2 displays the moisture content as a function of mastication time for bread (Figure 2A) 349 and crackers (Figure 2B). Bolus moisture content increased with mastication time, and more moisture was taken up at the beginning of mastication. More moisture uptake was observed for crackers compared to bread (carrier:time interaction, $F=17.1, \mathrm{p}<0.001$ ). The moisture content of single crackers increased from $2.7 \pm 0.1$ to $50.4 \pm 1.9 \%$ at the moment of swallowing, whereas

353 for single bread it increased from $34.4 \pm 0.5$ to $55.0 \pm 1.5 \%$. When toppings were added to the 354 carriers, the initial moisture content was larger than for the carriers alone, and moisture content 
increased to a lesser extent during mastication (carrier:topping interaction, $\mathrm{F}=2.3, \mathrm{p}=0.033$ ).

356 Moisture contents at the moment of swallowing varied between $48.1 \pm 1.2$ and $57.9 \pm 1.1 \mathrm{wt} \%$,

<Figure 2 about here> carriers significantly.

Saliva content increased with increasing mastication time, and more saliva was incorporated at the beginning of mastication. Figure 3 shows the averaged saliva content at the moment of swallowing in bread (Figure 3A) and crackers (Figure 3B). A higher saliva content was found for crackers compared to bread $(\mathrm{F}=96.4, \mathrm{p}<0.001)$, e.g. $0.97 \pm 0.06 \mathrm{~g} / \mathrm{g}$ dry weight for single crackers and $0.68 \pm 0.06 \mathrm{~g} / \mathrm{g}$ dry weight for single bread. In addition, a significant topping effect was found $(\mathrm{F}=29.0, \mathrm{p}<0.001)$. All three toppings significantly decreased the amount of saliva incorporated in both bread and crackers. In bread, firm cheese, cheese spread and mayonnaise decreased the saliva content from $0.68 \pm 0.06$ to $0.50 \pm 0.04,0.42 \pm 0.07$ and $0.46 \pm 0.07 \mathrm{~g} / \mathrm{g}$ dry weight, respectively. In the case of crackers, the toppings decreased the saliva content from $0.97 \pm 0.06$ to $0.66 \pm 0.05 \mathrm{~g} / \mathrm{g}$ dry weight for firm cheese, to $0.66 \pm 0.07 \mathrm{~g} / \mathrm{g}$ dry weight for cheese spread and to $0.74 \pm 0.08 \mathrm{~g} / \mathrm{g}$ dry weight for mayonnaise.

Significantly higher rates of saliva incorporation were found for crackers than bread samples $(\mathrm{F}=45.7, \mathrm{p}<0.001)($ Table 3$)$. As an example, the rate of saliva incorporation was $6.1 \pm 0.6 \mathrm{~g} / \mathrm{min}$ for single crackers and $4.5 \pm 0.5 \mathrm{~g} / \mathrm{min}$ for single bread. Furthermore, a significant topping effect was found $(\mathrm{F}=5.0, \mathrm{p}=0.003)$, and only mayonnaise increased the rate of saliva incorporation of 


\subsubsection{Mechanical properties of boli}

384 Figure 4 shows the average first peak force (associated to firmness) of the expectorated boli as 385 a function of mastication time. The peak force of all samples decreased over mastication time, in particular during the first $33 \%$ of total mastication time, to reach a plateau at around $66 \%$ of total mastication time (time effect, $\mathrm{F}=123.6, \mathrm{p}<0.001$ ). A significant carrier:topping effect was found $(\mathrm{F}=4.6, \mathrm{p}=0.004)$. Both the initial first peak force and its decrease during mastication was higher for crackers than for bread. For example, the peak force of single bread decreased from $0.92 \pm 0.08$ to $0.49 \pm 0.05 \mathrm{~N}$, while for the crackers a much larger decrease from $16.92 \pm 2.89$ to $0.67 \pm 0.06 \mathrm{~N}$ was found. Addition of toppings to carriers decreased the first peak force of both carriers, especially at the early stage of mastication. After $33 \%$ of total mastication time, the peak force of single bread was $1.04 \pm 0.08 \mathrm{~N}$. This decreased to $0.84 \pm 0.04,0.85 \pm 0.05$, and $0.35 \pm 0.02 \mathrm{~N}$ after addition of firm cheese, cheese spread and mayonnaise, respectively. In the case of crackers, the toppings decreased peak force at $33 \%$ of total mastication from $2.40 \pm 0.45$ to $2.17 \pm 0.35 \mathrm{~N}$ for firm cheese, to $1.07 \pm 0.09 \mathrm{~N}$ for cheese spread, and to $0.93 \pm 0.16 \mathrm{~N}$ for mayonnaise. On average, the addition of mayonnaise (grey square) showed the largest decrease in peak force for both bread and crackers and resulted in the lowest peak forces during all stages of mastication.

$<$ Figure 4 about here>

Adhesiveness of boli from bread and cracker increased with increasing mastication time (data not shown). Significant carrier:topping, carrier:time and topping:time interactions were observed (Table 2). At the moment of swallowing, bread and crackers did not differ in adhesiveness, but a significant topping effect $(\mathrm{F}=27.7, \mathrm{p}<0.001)$ and carrier:topping interaction $(\mathrm{F}=3.8, \mathrm{p}=0.01)$ were observed (Table 3 ). In the case of topping addition, the adhesiveness of bread and crackers either increased or decreased. Addition of toppings showed an increase for firm cheese and cheese spread and a decrease for mayonnaise.

410 Small, but statistically significant differences between samples and time points were found for 411 cohesiveness (Table 2). On average, bread boli were slightly more cohesive than cracker boli at all three time points (data not shown). Addition of firm cheese, cheese spread and mayonnaise increased the cohesiveness of single carriers in ascending order. At the moment of swallowing, 
414 a significant carrier effect $(\mathrm{F}=134.8, \mathrm{p}<0.001)$ and topping effect $(\mathrm{F}=12.5, \mathrm{p}<0.001)$ were 415 observed (Table 3).

\section{$416 \quad 3.3 \quad$ Characterization of sensory properties}

417 Figure 5A and Figure 5B show the sensory scores for dryness perception as a function of the 418 mastication time for bread and crackers. Dryness scores decreased with increasing mastication 419 time for all samples. After one chew, single crackers $(90.4 \pm 2.1 \mathrm{~mm}$, Figure 5B) were perceived 420 drier than single bread $(65.4 \pm 3.4 \mathrm{~mm}$, Figure 5A). A larger absolute decrease in dryness perception was observed for crackers than bread (carrier:time interaction, $F=15.0, p<0.001$ ). However, a difference in dryness between the carriers was maintained through mastication, and crackers $(62.3 \pm 4.2 \mathrm{~mm})$ were still perceived drier than bread $(45.3 \pm 3.2 \mathrm{~mm})$ at the end of mastication. Addition of toppings decreased dryness perception at all four mastication time points for both carriers $(\mathrm{F}=115.3, \mathrm{p}<0.001)$ (Figure 5A, 5B). Although all three toppings decreased dryness perception, the type of topping added to the carriers determined the degree of the decrease. At the end of mastication, a significant carrier effect $(F=52.1, p<0.001)$ and topping effect $(\mathrm{F}=25.3, \mathrm{p}<0.001)$ were observed. Dryness scores of bread decreased significantly from $45.3 \pm 3.2$ to $36.6 \pm 3.0 \mathrm{~mm}$ after addition of firm cheese, to $28.4 \pm 2.8 \mathrm{~mm}$ after addition of cheese spread, and to $29.0 \pm 3.3 \mathrm{~mm}$ after addition of mayonnaise $(\mathrm{p}<0.05)$. Similar results were found for the dryness perception of crackers, and dryness scores of crackers significantly decreased from $62.3 \pm 4.2$ to $48.5 \pm 3.8,44.6 \pm 3.5$ and $36.7 \pm 3.3 \mathrm{~mm}$ after addition of firm cheese, cheese spread, and mayonnaise, respectively $(\mathrm{p}<0.05)$. Overall, the absolute decrease in dryness was largest after the addition of mayonnaise, followed by cheese spread and then firm cheese for both carriers at all mastication time points.

Figure 5C and Figure 5D display the sensory scores for firmness perception as a function of the mastication time for bread and crackers. Firmness scores decreased with increasing mastication time for all samples. After one chew, single crackers (86.6 $\pm 2.6 \mathrm{~mm}$, Figure 5D) were perceived firmer than single bread $(58.3 \pm 3.5 \mathrm{~mm}$, Figure $5 \mathrm{C})$. The absolute decrease in firmness through mastication was greater for crackers than for bread, resulting in similar firmness intensities at 441 the moment of swallowing $(\mathrm{F}=1.9, \mathrm{p}=0.166)$. Addition of toppings did not significantly change 442 the firmness scores after one chew. Addition of toppings to carriers decreased firmness scores 443 throughout mastication (Figure 5C, 5D), but the effect depended on the type of topping. The 444 absolute decrease in firmness perception was greatest after the addition of mayonnaise, 445 followed by cheese spread, and then firm cheese. At the moment of swallowing, a significant 
446 topping effect was found $(\mathrm{F}=10.2, \mathrm{p}<0.001)$, and addition of mayonnaise significantly 447 decreased the firmness intensity perception of both carriers (Table 3 ).

448 Stickiness increased with increasing mastication time, especially at the early stage of 449 mastication (data not shown). At the moment of swallowing, no significant difference in 450 stickiness was observed between bread and crackers $(\mathrm{F}=0.4, \mathrm{p}=0.553)$, but a significant topping 451 effect was found $(\mathrm{F}=4.6, \mathrm{p}=0.004)$. Addition of mayonnaise to the carriers significantly 452 decreased stickiness at the moment of swallowing $(\mathrm{p}<0.05)$ (Table 3); stickiness of single bread 453 decreased from $58.8 \pm 2.7$ to $48.7 \pm 3.8 \mathrm{~mm}$ after addition of mayonnaise, whereas the stickiness 454 of cracker decreased from $59.9 \pm 3.5$ to $54.1 \pm 3.7 \mathrm{~mm}$.

455 Flavor intensity slightly increased with increasing mastication times (Figure 5E, 5F). Overall, 456 flavor intensity was driven by the presence of toppings rather than carriers. Addition of toppings 457 to carriers increased flavor intensity scores at all four mastication time points. The degree of 458 the increase was determined by the type of topping that was added to the carriers. The absolute 459 increase in flavor intensity of both carriers was largest after the addition of mayonnaise (flavor 460 intensity scores increased by a factor of 3), followed by cheese spread and firm cheese (flavor 461 intensity scores increased by a factor of 2). Furthermore, the absolute increase in flavor intensity 462 was larger when toppings were added to bread than crackers. At the moment of swallowing 463 (Table 3), the flavor intensity of bread without topping, with firm cheese, cheese spread and 464 mayonnaises were $26.7 \pm 2.9,56.8 \pm 3.3,55.6 \pm 2.8$ and $68.9 \pm 2.8 \mathrm{~mm}$, whereas this was $26.0 \pm 3.1$, $46550.4 \pm 2.7,44.2 \pm 3.4$ and $60.9 \pm 2.7 \mathrm{~mm}$ for crackers, respectively. 


\section{Discussion}

We investigated the contribution of toppings to carriers on the oral processing behavior and dynamic sensory perception of composite foods. Carriers (bread and crackers) and toppings (firm cheese, cheese spread and mayonnaise) were used as single foods, and they were combined into composite foods (carrier with topping) with contrasting composition, mechanical properties and sensory characteristics.

As was seen in Figure 1, spreading the toppings cheese spread and mayonnaise on carrier foods reduced total mastication time and number of chews until swallowing, and no effect was found for firm cheese. It is interesting to note that the weight of carriers alone was $2.1 \mathrm{~g}$, while the weight of carrier-topping combinations doubled to $4.2 \mathrm{~g}$ (i.e. $2.1 \mathrm{~g}$ carrier and $2.1 \mathrm{~g}$ topping). Thus, even though addition of toppings to carriers doubled the sample weight, the carriers shortened the total mastication time in the case of cheese spread and mayonnaise while it remained similar for firm cheese. This implies that toppings influenced the mastication behavior of carriers. These data are consistent with those of Gavião et al. (2004) and Engelen et al. (2005) who showed that spreading butter on toast decreased the time and number of chewing cycles until swallowing. In those works, it was hypothesized that toppings facilitated saliva in the bolus formation of carriers leading to boli that are broken down and lubricated enough to be safely swallowed after shorter mastication times and less chews. This is indeed confirmed by the results of our current study. Addition of toppings to carriers led to less saliva incorporation (Figure 3) and a faster decrease in first peak force (Figure 4) of carrier boli. Addition of toppings to carriers led to decreased dryness and firmness perception (Figure 5). Due to their dry character, both bread and crackers require an increase in lubrication behavior and reduction of structure before they can be swallowed safely. These results show that toppings moistened and softened the bolus, and consequently less time had to be spent on reducing structure and increasing lubrication to safely swallow earlier. This confirms the hypothesis that toppings assist saliva in bolus formation.

Comparing the two different carriers (bread versus cracker), crackers have a lower moisture content and are harder than bread (Table 1). It is known that dry and/or hard foods are processed in the mouth for longer time because they require more saliva and/or need to be softened more (Chen, Khandelwal, Liu, \& Funami, 2013; J. B. Hutchings \& Lillford, 1988). This is confirmed by the present study, which found longer mastication times and higher number of chews until swallowing for crackers than for bread (Figure 1). Hence, dry and/or hard foods were expected to benefit more from the facilitating effects of toppings than moist and/or soft foods. We indeed 
found that for crackers, the addition of toppings resulted in a larger absolute decrease in total mastication time and number of chews until swallowing (Figure 1), and this effect was less pronounced in bread. These findings are in line with previous studies. Engelen et al. (2005) reported that adding butter to toast and cake reduced the number of chewing cycles until swallowing, whereas no effect was found for bread (higher initial moisture content, softer). In addition, adding fluids to toast (low moisture content, hard), cake (low moisture content), and peanuts (low moisture content, hard) decreased the number of chews until swallowing, whereas this effect was not found for cheese (soft) and carrots (high moisture content, hard)(Pereira, de Wijk, Gavião, \& van der Bilt, 2006; Pereira, Gavião, Engelen, \& Van Der Bilt, 2007; Van Der Bilt, Engelen, Abbink, \& Pereira, 2007). These studies clearly indicate that mainly dry foods benefit from the facilitating effects of fluids or toppings leading to shortened mastication times, but no data was found on the bolus properties underlying this observation. Our present study highlights that indeed the bolus formation of crackers rather than bread was affected by the presence of toppings. Absolute decrease in saliva incorporation and first peak force after addition of toppings was larger for crackers compared to bread (Figure 3 and 4). Thus, dry and hard crackers with a low moisture content absorbed more moisture from the toppings than soft bread with a higher moisture content.

Different toppings (firm cheese, cheese spread and mayonnaise) impacted oral processing behavior and sensory perception of carriers differently. On average, mayonnaise had the largest impact on oral processing behavior of carriers, followed by cheese spread and only a small influence by firm cheese was observed. Similar findings were found for dryness and firmness perception. It appears that the higher the contrast in terms of mechanical properties and/or moisture content between toppings and carriers, the larger the influence of toppings on oral processing behavior and texture perception of carrier foods. These different effects of the three toppings are likely to be caused by variations in their initial composition and product properties.

526 It seems that incorporation of toppings into bread and cracker boli depends on its consistency.

527 Mayonnaise has the highest moisture content and can be characterized as a plastic liquid-like 528 topping (Table 1). Due to its high moisture content and liquid behavior it was easily mixed with the carriers to form a cohesive bolus. Mayonnaise thereby softened the carrier boli most effectively (Figure 4) and consequently decreased dryness and firmness scores largely (Figure 5). Cheese spread also decreased mastication times and number of chews of carriers, but to a lesser extent than mayonnaise. This could be attributed to less moisture incorporation into the carrier boli due to its semi-solid texture and slightly lower moisture content. Another possible 
534 explanation might be found in differences in adhesiveness between cheese spread and 535 mayonnaise. Increased adhesiveness of foods requires longer cycle duration and increased muscle activities to remove it from oral surfaces and thereby increasing total mastication time. This has been shown for caramels (Çakir et al., 2012). Cheese spread is more adhesive than mayonnaise and was perceived more sticky, which might have contributed to longer mastication time and a higher number of chews. Firm cheese had the lowest impact on both oral processing behavior and sensory perception of carriers, which can be explained by its solid-like consistency and limited ability to incorporate moisture in the boli. The facilitating effects of toppings on bolus formation of bread and crackers depends strongly on the consistency of toppings. Fat content is not likely to have caused the differences between toppings found in the present study, since all three toppings contained similar fat content (Table 1).

545 Figure 6 shows a Principal Component Analysis (PCA) bi-plot of carriers with and without 546 toppings over oral processing parameters throughout mastication to summarize the oral 547 processing pathways of such foods. Mastication behavior parameters were taken at three stages during oral processing (i.e. 0-33, 33-66 and 66-100\% of total mastication time) and bolus properties were taken at three time points throughout oral processing $(33,66$ and $100 \%$ of total mastication time). As can be seen, bread samples are located on the left side of the first the principal component (PC1) and the cracker samples are located on the right side of PC1 (X axis, $55 \%$ ). Oral processing of bread starts near bolus adhesiveness and cohesiveness, whereas oral processing of crackers starts near vertical jaw movements, saliva incorporation rate and bolus

554 first peak force. Interestingly, all foods move towards the left and towards the bottom part of the plot with increasing mastication time, moving towards the parameters moisture content and saliva content. Carriers with toppings are positioned relatively close to the corresponding single carrier, showing that the oral processing pathways of composite foods are relatively close to that of the single carrier. This indicates that the oral processing pathways and oral processing behavior are driven by carriers rather than toppings, which might be due to the dominating texture of the carriers. This is consistent with previous studies that investigated model foods, in which a hard layer was found to dominate the oral processing behavior of bi-layer model gels containing hard and soft layers (Devezeaux de Lavergne et al., 2016). In addition, the hard crust was found to dominate the dynamic texture perception of bread crumb with crust sample throughout consumption (Gao et al., 2017). Although the pathways of carriers with and without toppings were similar, the presence of a topping induced some changes to the oral processing pathways of single carriers (Figure 6). Carriers with firm cheese and cheese spread are 
positioned closest to its single carrier, whereas carriers with mayonnaise are positioned more 568 towards the left top part of the plot. This illustrates that the addition of mayonnaise had the highest impact on the oral processing pathways of carriers.

$<$ Figure 6 about here>

When carrier foods were combined with toppings, the oral processing pathways and texture perception were influenced by both carriers and toppings, but in different ways. Carriers drove the oral processing behavior and texture perception because these need to be broken down into smaller particles and need to be lubricated before swallowing. Toppings moistened the carrier foods by which they adapted their oral processing pathways and texture perception.

Flavor perception is another important aspect of the dynamic sensory perception of composite foods. Flavor intensity increased with increasing mastication time. The addition of toppings to carriers increased flavor intensity scores at all four time points, indicating that flavor perception throughout consumption was driven by the toppings rather than the carriers. This increase in flavor intensity by adding toppings might be one of the factors that explains why bread and crackers are frequently consumed together with toppings. Besides, flavor intensities were lower for cracker-topping combinations than for bread-topping combinations (Figure 5, Table 3). This might be explained by the dry character of crackers, dry crackers might take up the topping to a larger extent than moist bread, leading to a lower flavor intensity perception. Another explanation might be the hard character of the crackers, hard cracker require more oral breakdown than soft bread, which might distract consumers attention from flavor perception. This result is in line with previous studies on single foods, showing that an increase in hardness of gels and candies decreased the perceived flavor intensities (Boland, Delahunty, \& van Ruth, 2006; Saint-Eve et al., 2011).

592 The present study has important implications for food design, and these insights allow the 593 tailoring of oral processing behavior and subsequent consumer perception of composite foods. 594 For example, adding toppings facilitated mastication and bolus formation of carrier foods, 595 which could be applied in foods for elderly or people with decreased eating capabilities. 596 Although this study focuses on the oral processing behavior and sensory perception of 597 composite foods, the findings may well have implications for food intake and satiation. 
Addition of toppings to carrier foods decreased oro-sensory exposure time while it increased

599 the total energy content of the food consumed. This might cause faster consumption of higher energy dense foods and subsequently this may result in increased consumers food intake.

\section{Conclusion}

602 This study shows that toppings (firm cheese, cheese spread and mayonnaise) impacted the mastication behavior, bolus formation and dynamic sensory perception of carrier foods (bread, crackers). Carriers to which semi-solid cheese spread and liquid-like mayonnaise were added were chewed for a shorter time and with fewer chews than single carriers bread and crackers, although twice the mass of food was orally processed. No effect was found for solid firm cheese. Less saliva incorporation and a faster decrease in bolus peak forces were observed after addition of toppings to carriers. Addition of toppings also decreased dryness and firmness perception, whereas flavor perception was increased at all stages of mastication. We conclude that toppings assist saliva in bolus formation of bread and crackers. In particular, liquid-like mayonnaise and semi-solid cheese spread moistened and softened the carriers, leading to shorter mastication times and a lower number of chewing cycles to break down and lubricate boli enough to be safely swallowed. As the effects were most pronounced after the addition of mayonnaise,

614 followed by cheese spread and firm cheese, the consistency of the toppings seems to play a 615 major role. More liquid-like toppings are more easily mixed with the carriers, leading to faster moisture incorporation into the bolus and a faster softening of the bolus. The effects of toppings were more pronounced in crackers than in bread, indicating that also the dryness of the carriers affects oral processing. Thus, oral processing depends on the mechanical properties of both the carrier and the topping. To develop a full understanding on the role of single foods on the oral processing behavior and sensory perception of composite foods, additional studies investigating carriers and toppings with systematically varied product properties will be required.

\section{Acknowledgements}

623 The authors thank Monica Aguayo-Mendoza for sharing her expertise on the conduction of the 624 video recordings, Alvaro Garcia-Fuentes for his technical support with respect to the data 625 analysis of the videos, and Betina Piqueras-Fiszman for her help with statistical data analysis. 626 The project is funded by TiFN, a public-private partnership on precompetitive research in food 627 and nutrition. The public partners are responsible for the study design, data collection and 
analysis, decision to publish, and preparation of the manuscript. The private partners have contributed to the project through regular discussion.

\section{References}

Boland, A. B., Delahunty, C. M., \& van Ruth, S. M. (2006). Influence of the texture of gelatin gels and pectin gels on strawberry flavour release and perception. Food Chemistry, 96(3), 452-460.

Çakir, E., Koç, H., Vinyard, C. J., Essick, G., Daubert, C. R., Drake, M., et al. (2012). Evaluation of texture changes due to compositional differences using oral processing. Journal of Texture Studies, 43(4), 257-267.

Campbell, C. L., Wagoner, T. B., \& Foegeding, E. A. (2016). Designing foods for satiety: The roles of food structure and oral processing in satiation and satiety. Food Structure. Chen, J. (2009). Food oral processing-A review. Food Hydrocolloids, 23(1), 1-25.

Chen, J. (2015). Food oral processing: Mechanisms and implications of food oral destruction. Trends in Food Science and Technology, 45(2), 222-228.

Chen, J., Khandelwal, N., Liu, Z., \& Funami, T. (2013). Influences of food hardness on the particle size distribution of food boluses. Arch Oral Biol, 58(3), 293-298.

Cherdchu, P., \& Chambers, E. (2014). Effect of carriers on descriptive sensory characteristics: A case study with soy sauce. Journal of Sensory Studies, 29(4), 272-284.

Devezeaux de Lavergne, M., Tournier, C., Bertrand, D., Salles, C., van de Velde, F., \& Stieger, M. (2016). Dynamic texture perception, oral processing behaviour and bolus properties of emulsion-filled gels with and without contrasting mechanical properties. Food Hydrocolloids, 52, 648-660.

Devezeaux de Lavergne, M., van de Velde, F., \& Stieger, M. (2017). Bolus matters: the influence of food oral breakdown on dynamic texture perception. Food \& Function, $8(2), 464-480$.

Devezeaux de Lavergne, M., van de Velde, F., van Boekel, M. A. J. S., \& Stieger, M. (2015). Dynamic texture perception and oral processing of semi-solid food gels: Part 2: Impact of breakdown behaviour on bolus properties and dynamic texture perception. Food Hydrocolloids, 49, 61-72.

Engelen, L., Fontijn-Tekamp, A., \& Van Der Bilt, A. (2005). The influence of product and oral characteristics on swallowing. Arch Oral Biol, 50(8), 739-746. 
659

660

661

662

663

664

665

666

667

668

669

670

671

672

673

674

675

676

677

678

679

680

681

682

683

684

685

686

687

688

689

690

691

Forde, C. G. (2018). From perception to ingestion; the role of sensory properties in energy selection, eating behaviour and food intake. Food Quality and Preference, 66, 171177.

Gao, J., Ong, J. J.-X., Henry, J., \& Zhou, W. (2017). Physical breakdown of bread and its impact on texture perception: A dynamic perspective. Food Quality and Preference, 60, 96-104.

Gavião, M. B. D., Engelen, L., \& Van Der Bilt, A. (2004). Chewing behavior and salivary secretion. European Journal of Oral Sciences, 112(1), 19-24.

Hutchings, J. B., \& Lillford, P. J. (1988). The perception of food texture - The philosophy of the breakdown path Journal of Texture Studies, 19(2), 103-115.

Hutchings, S. C., Foster, K. D., Bronlund, J. E., Lentle, R. G., Jones, J. R., \& Morgenstern, M. P. (2011). Mastication of heterogeneous foods: Peanuts inside two different food matrices. Food Quality and Preference, 22(4), 332-339.

Jourdren, S., Saint-Eve, A., Panouillé, M., Lejeune, P., Déléris, I., \& Souchon, I. (2016). Respective impact of bread structure and oral processing on dynamic texture perceptions through statistical multiblock analysis. Food Research International, 87, 142-151.

Koc, H., Vinyard, C. J., Essick, G. K., \& Foegeding, E. A. (2013). Food oral processing: Conversion of food structure to textural perception. Annu Rev Food Sci Technol, 4(1), 237-266.

Laguna, L., \& Chen, J. (2016). The eating capability: Constituents and assessments. Food Quality and Preference, 48, 345-358.

Larsen, D. S., Tang, J., Ferguson, L., Morgenstern, M. P., \& James, B. J. (2015). Oral Breakdown of Texturally Complex Gel-Based Model Food. Journal of Texture Studies.

Le Bleis, F., Chaunier, L., Montigaud, P., \& Della Valle, G. (2016). Destructuration mechanisms of bread enriched with fibers during mastication. Food Research International, 80, 1-11.

Meinert, L., Frøst, M. B., Bejerholm, C., \& Aaslyng, M. D. (2011). Enhancing the sensory quality of vegetables by decreasing some less-desired sensory properties with low-fat pork gravy. Journal of Culinary Science and Technology, 9(2), 113-131.

Mosca, A. C., \& Chen, J. (2016). Food oral management: Physiology and objective assessment. Current Opinion in Food Science, 9, 11-20. 
Panouillé, M., Saint-Eve, A., Déléris, I., Le Bleis, F., \& Souchon, I. (2014). Oral processing and bolus properties drive the dynamics of salty and texture perceptions of bread. Food Research International, 62, 238-246.

Paulsen, M. T., Ueland, T., Nilsen, A. N., Öström, Å., \& Hersleth, M. (2012). Sensory perception of salmon and culinary sauces - An interdisciplinary approach. Food Quality and Preference, 23(2), 99-109.

Pereira, L. J., de Wijk, R. A., Gavião, M. B. D., \& van der Bilt, A. (2006). Effects of added fluids on the perception of solid food. Physiology and Behavior, 88(4-5), 538-544.

Pereira, L. J., Gavião, M. B. D., Engelen, L., \& Van Der Bilt, A. (2007). Mastication and swallowing: Influence of fluid addition to foods. Journal of Applied Oral Science, 15(1), 55-60.

Saint-Eve, A., Déléris, I., Panouillé, M., Dakowski, F., Cordelle, S., Schlich, P., et al. (2011). How texture influences aroma and taste perception over time in candies. Chemosensory Perception, 4(1-2), 32-41.

Scholten, E. (2017). Composite foods: from structure to sensory perception. Food \& Function, 8(2), 481-497.

Szczesniak, A. S., \& Kahn, E. L. (1984). Texture contrasts and combinations: A valued consumer attribute. Journal of Texture Studies, 15(3), 285-301.

Tang, J., Larsen, D. S., Ferguson, L., \& James, B. J. (2017). Textural Complexity Model Foods Assessed with Instrumental and Sensory Measurements. Journal of Texture Studies, 48(1), 9-22.

Van Der Bilt, A., Engelen, L., Abbink, J., \& Pereira, L. J. (2007). Effects of adding fluids to solid foods on muscle activity and number of chewing cycles. European Journal of Oral Sciences, 115(3), 198-205.

Wang, X., \& Chen, J. (2017). Food oral processing: Recent developments and challenges. Current Opinion in Colloid \& Interface Science, 28, 22-30.

Witt, T., \& Stokes, J. R. (2015). Physics of food structure breakdown and bolus formation during oral processing of hard and soft solids. Current Opinion in Food Science, 3, 110-117. 
Figure 1: Total mastication time (dark grey) and number of chews (light grey) until swallowing for bread (A) and crackers (B) without topping and with different toppings (firm cheese, cheese spread and mayonnaise). Error bars represent standard error of the mean. Dashed lines represent averaged value of single carriers ( $\mathrm{n}=18$ subjects, in triplicate). Different letters indicate significant differences between means $(\mathrm{p}<0.05)$.

Figure 2: Bolus moisture content (wt\%) for bread (A) and crackers (B) with and without toppings ( $\mathrm{n}=18$ subjects). Time points correspond to 33, 66 and $100 \%$ of total mastication time. The initial moisture content of samples is presented at $\mathrm{t}=0 \mathrm{~s}$. Error bars represent standard error of the mean. Dotted lines are added to guide the eye.

Figure 3: Bolus saliva content at moment of swallowing in bread (A) and crackers (B) with and without toppings. Error bars represent standard error of the mean. Dashed lines represent averaged value of single carriers ( $\mathrm{n}=18$ subjects). Different letters indicate significant differences $(\mathrm{p}<0.05)$.

Figure 4: Bolus peak force during first puncture cycle (associated to firmness) for bread (A) and crackers (B) with and without toppings. Time points correspond to 33, 66 and $100 \%$ of total mastication time. Error bars represent standard error of the mean ( $\mathrm{n}=18$ subjects, in duplicate). Dashed lines are added to guide the eye.

Figure 5: Dryness, firmness and flavor intensity for bread and crackers with and without toppings determined by progressive profiling ( $\mathrm{n}=18$ subjects, in duplicate): (A) dryness of bread; (B) dryness of crackers; (C) firmness of bread; (D) firmness of crackers; (E) flavor intensity of bread; and (F) flavor intensity of crackers. Time points correspond to 1 chew and 33, 66 and $100 \%$ of total mastication time. Error bars represent standard error of the mean. Dashed lines are added to guide the eye.

Figure 6: Principal component analysis (PCA) representing oral processing pathways of bread and crackers with and without toppings. Mastication behavior parameters (number of chews, chewing frequency, maximum vertical and lateral jaw movements) were taken at three stages during oral processing (i.e. $0-33,33-66$ and $66-100 \%$ of total mastication time). Bolus properties (moisture content, saliva content, saliva incorporation rate, first peak force, adhesiveness and cohesiveness) were taken at three time points throughout oral processing (33, 66 and $100 \%$ of total mastication time). Bread samples are presented in gray, and cracker 
753 samples in black. Lines were drawn to guide the eye. Pictures of single carriers and carriers 754 with mayonnaise were presented close to the corresponding time points for illustration 755 purposes.

756 
Figure 1:

\section{(A) bread}

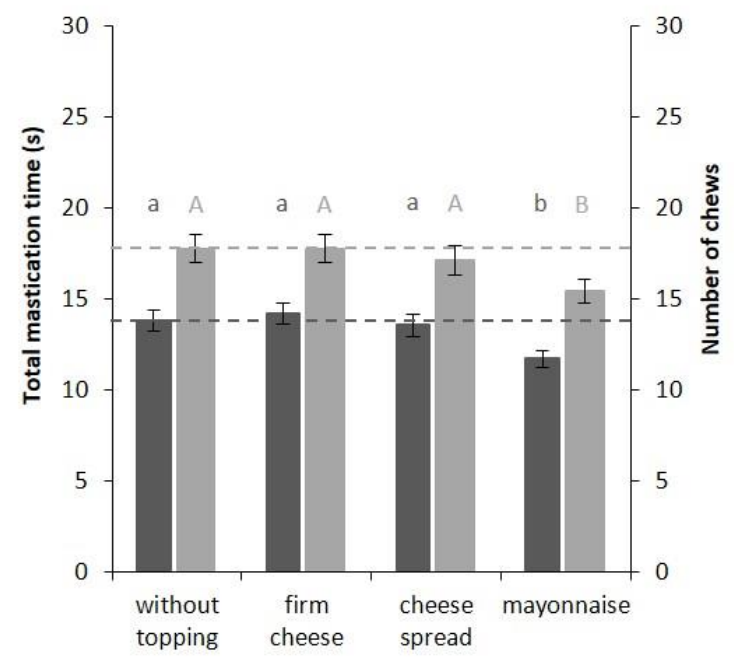

\section{(B) crackers}

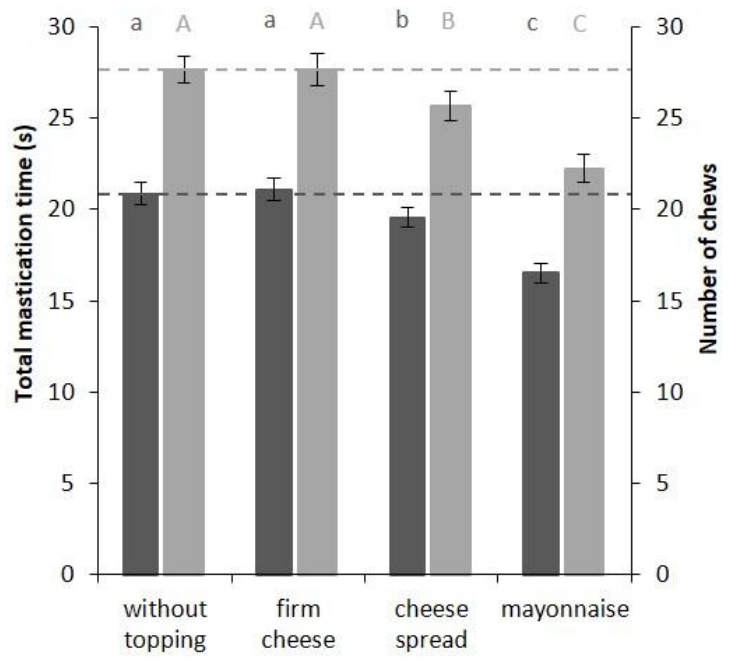

759

Figure 2:

(A) bread

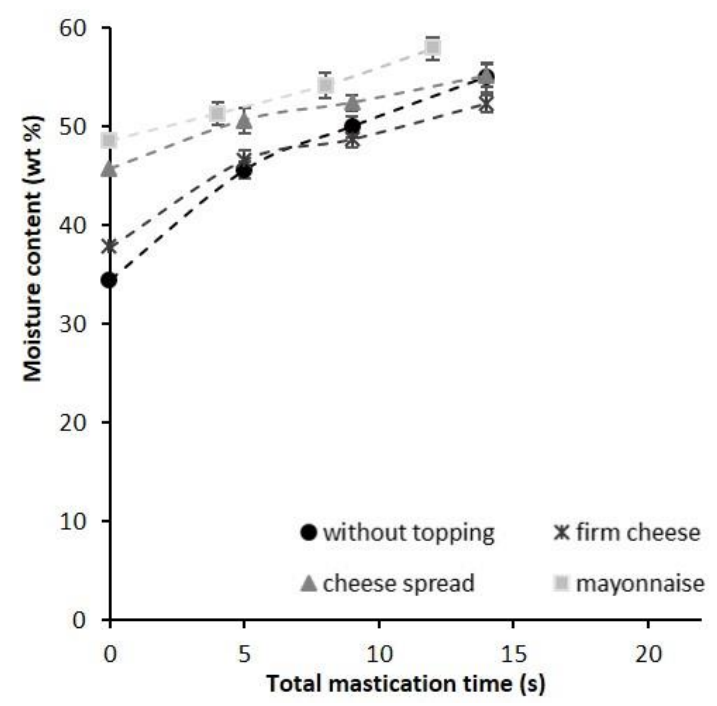

(B) crackers

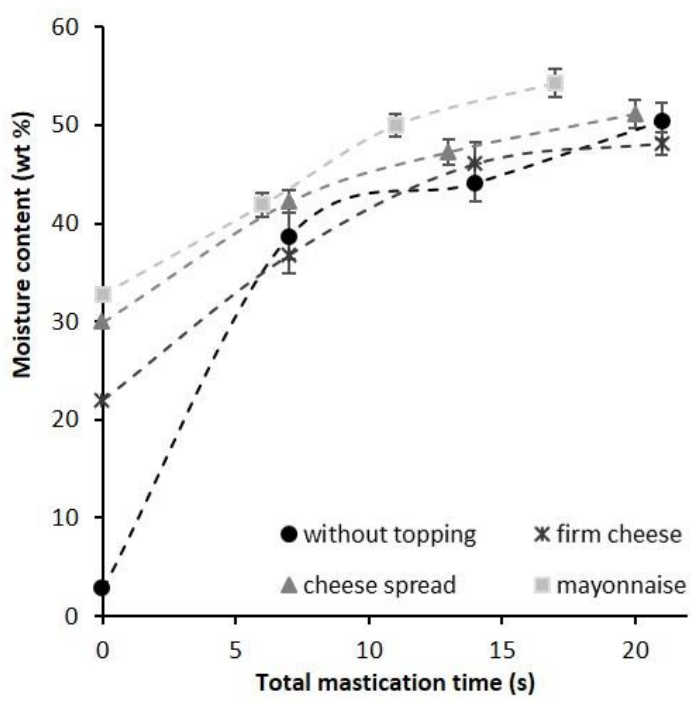


Figure 3:

(A) bread

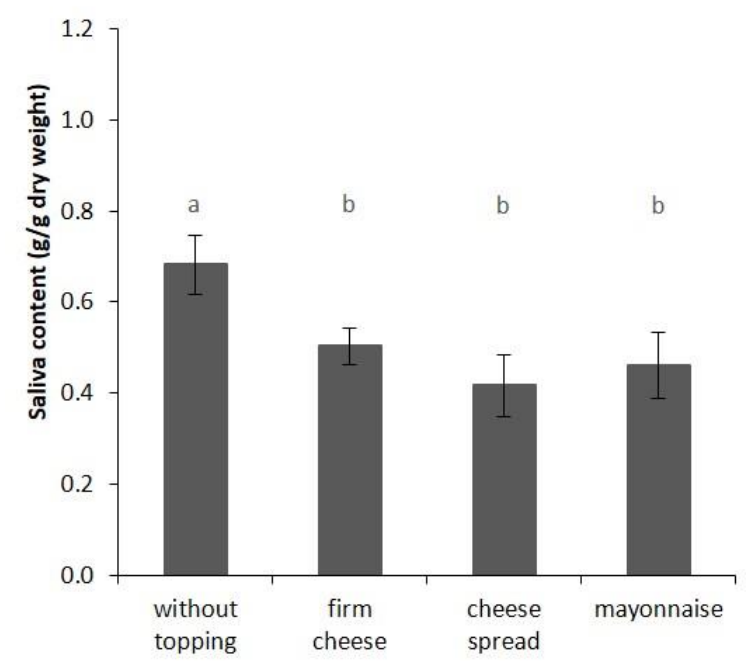

(B) crackers

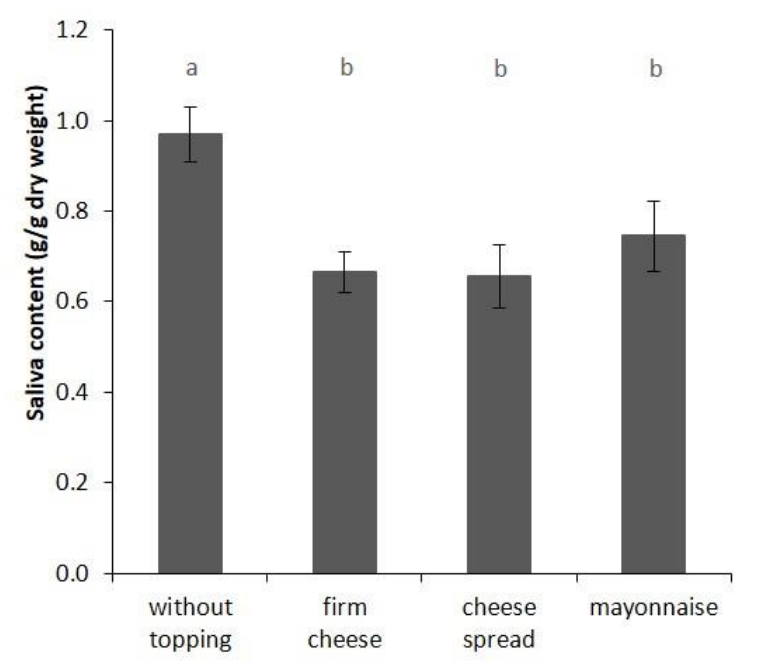

765

766

Figure 4:

(A) bread

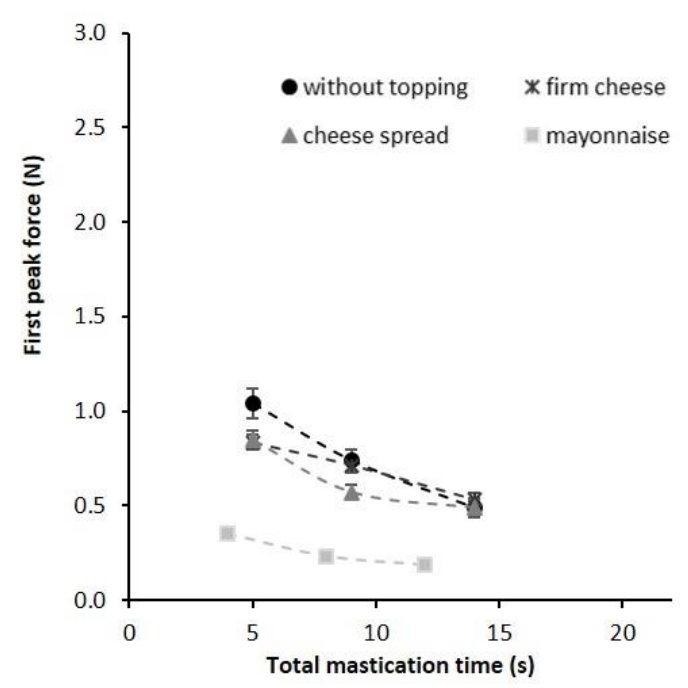

(B) crackers

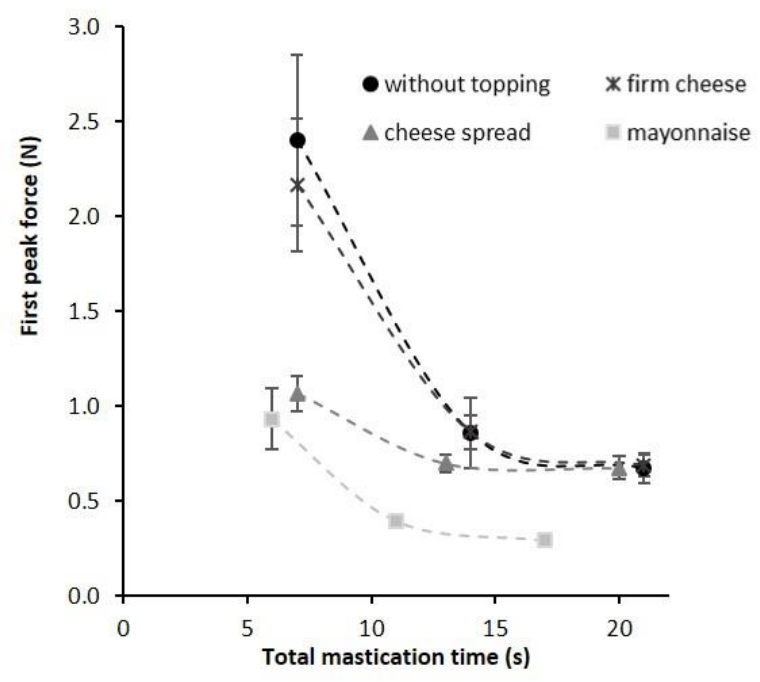




\section{(A) bread}

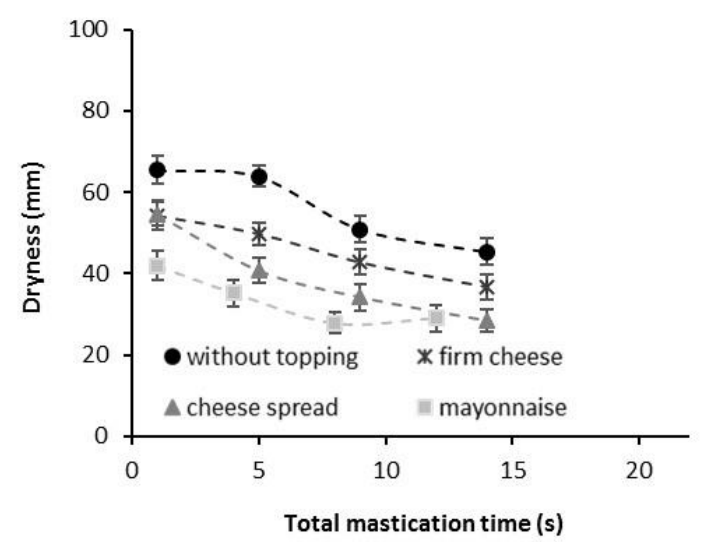

(C) bread

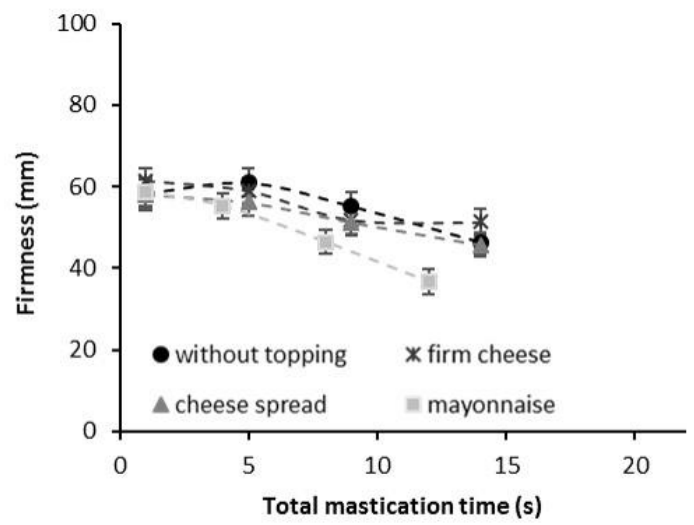

(E) bread

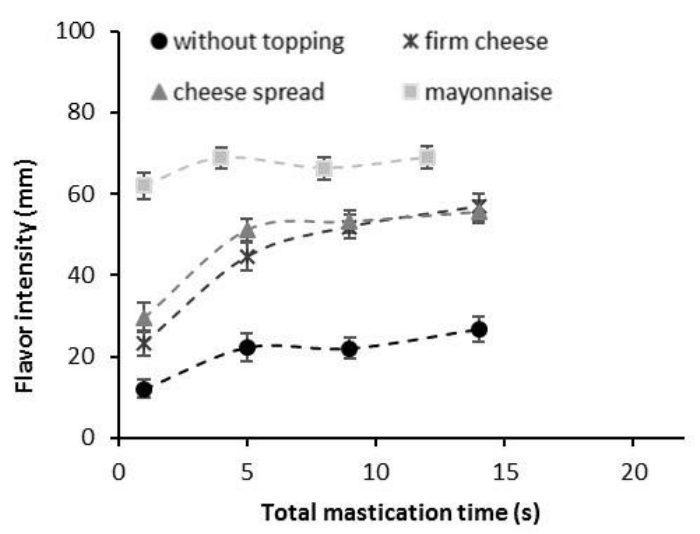

(B) crackers

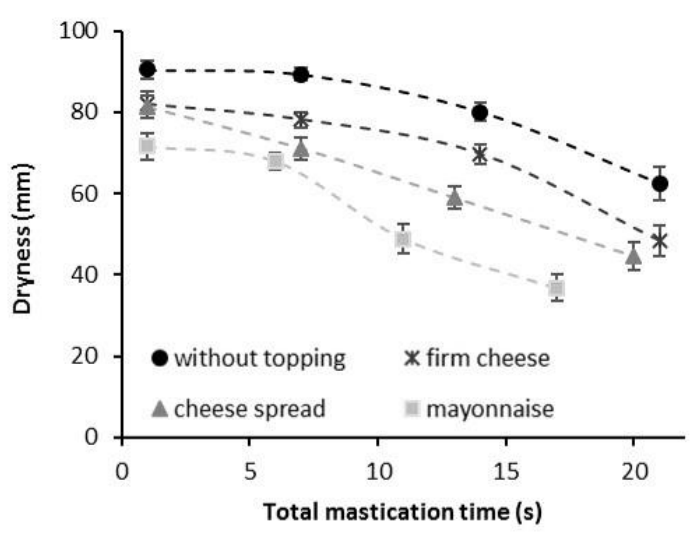

(D) crackers

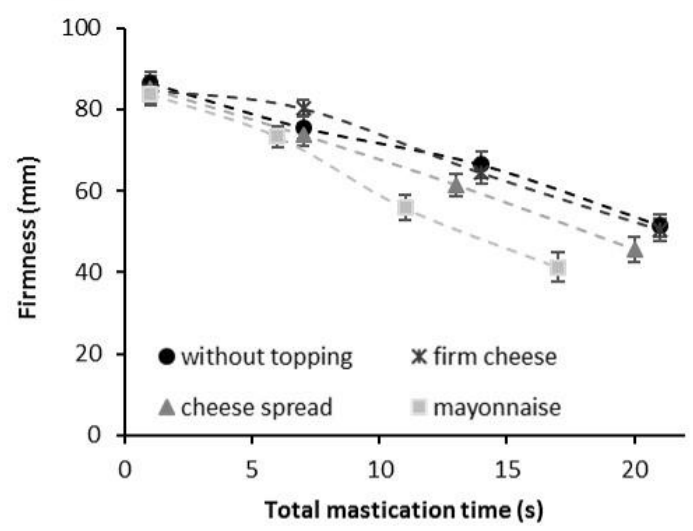

(F) crackers

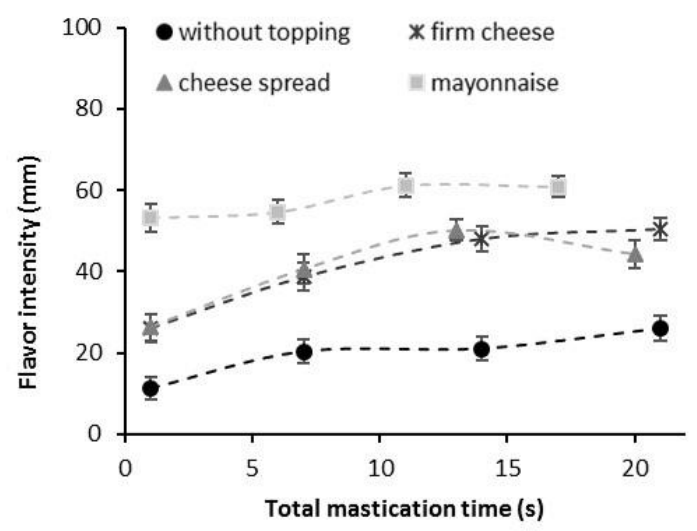




\section{$771 \quad$ Figure 6:}

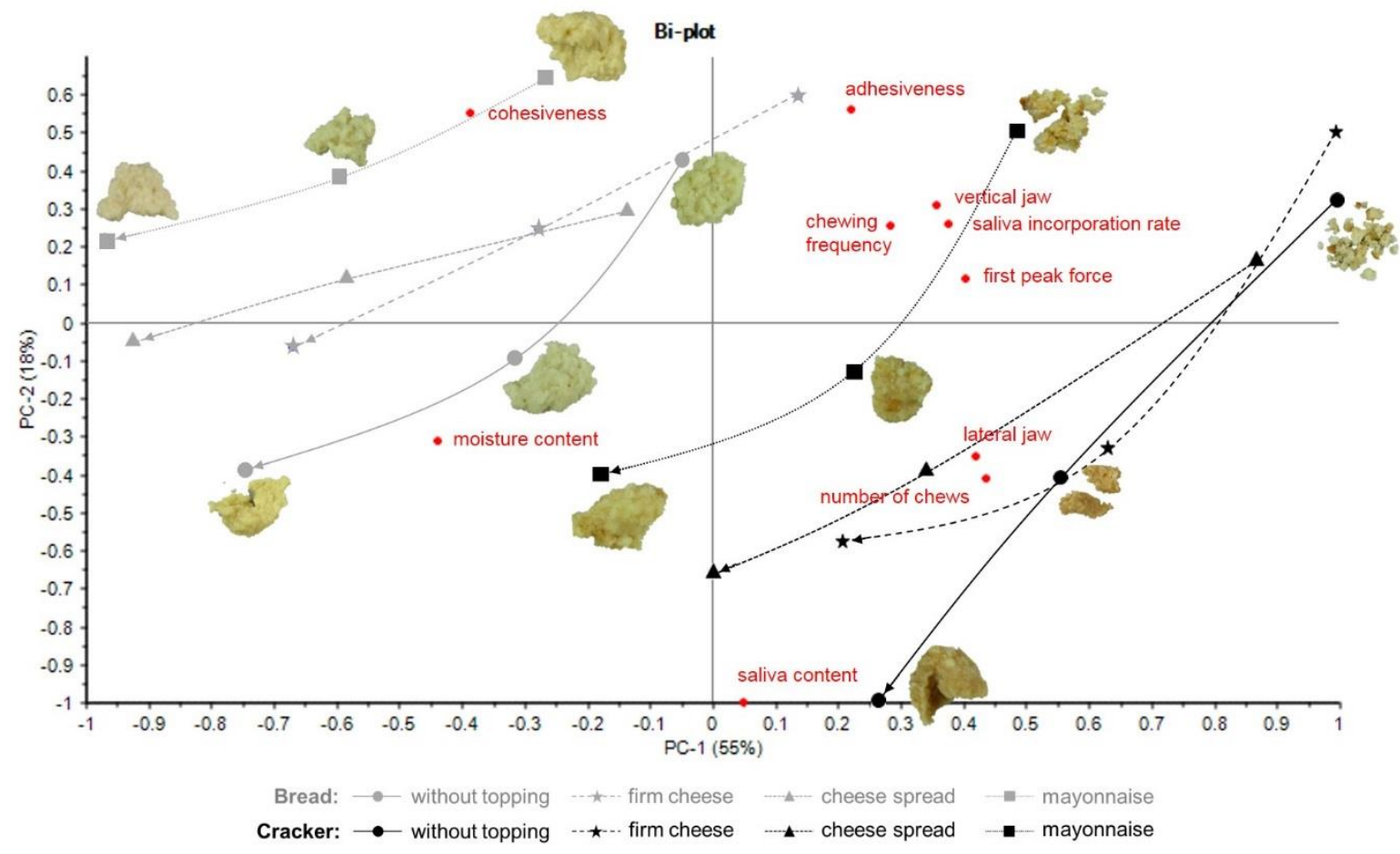




\section{Tables}

775 Table 1: Overview of composition (fat and moisture content), physical-chemical properties 776 (water activity, first peak force, adhesiveness, cohesiveness, texture category) and serving size 777 of single foods ( 2 carriers, 3 toppings). Mean values \pm standard error of the mean are given.

778 Table 2: Fixed effects of linear mixed models carried out for all mastication parameters, bolus 779 properties and sensory properties of single carriers and carrier-topping combinations.

780 Table 3: Fixed effects and descriptives (mean \pm SE) of bolus properties and sensory 781 characteristics at moment of swallowing $(\mathrm{t}=100 \%)$ for bread and crackers with and without 782 toppings, derived by linear mixed models. 
Table 1:

\begin{tabular}{|c|c|c|c|c|c|c|c|c|}
\hline Single foods & $\begin{array}{l}\text { Fat content* } \\
(\mathrm{wt} \%)\end{array}$ & $\begin{array}{l}\text { Moisture content } \\
(\mathrm{wt} \%)\end{array}$ & Water activity & $\begin{array}{l}\text { First peak force*** } \\
(\mathrm{N})\end{array}$ & $\begin{array}{l}\text { Adhesiveness** } \\
(\mathrm{g} \cdot \mathrm{s})\end{array}$ & Cohesiveness** & Texture category & $\begin{array}{l}\text { Serving size } \\
(\mathrm{g})\end{array}$ \\
\hline \multicolumn{9}{|l|}{ Carriers } \\
\hline Bread & 4 & $34.4 \pm 1.0$ & $0.91 \pm 0.002$ & $0.92 \pm 0.08$ & $-1.9 \pm 4.9$ & $0.77 \pm 0.06$ & Soft solid & 2.1 \\
\hline Cracker & 4 & $2.7 \pm 0.2$ & $0.21 \pm 0.015$ & $16.92 \pm 2.89$ & $-7.7 \pm 9.4$ & $0.06 \pm 0.03$ & Hard solid & 2.1 \\
\hline
\end{tabular}

\section{Toppings}

\begin{tabular}{|c|c|c|c|c|c|c|c|c|}
\hline Firm cheese & 31 & $41.1 \pm 0.5$ & $0.96 \pm 0.004$ & $4.00 \pm 0.05$ & $-103.1 \pm 21.9$ & $0.75 \pm 0.01$ & Soft solid & 2.1 \\
\hline Cheese spread & 30 & $57.0 \pm 0.1$ & $0.98 \pm 0.001$ & $1.11 \pm 0.02$ & $-221.9 \pm 47.4$ & $0.25 \pm 0.02$ & Semi-solid & 2.1 \\
\hline Mayonnaise & 27 & $62.8 \pm 0.2$ & $0.97 \pm 0.001$ & - & - & - & Plastic liquid & 2.1 \\
\hline
\end{tabular}

$784 *$ The fat content was taken from the packages.

$785 * *$ The mechanical properties of mayonnaise were not analyzed since mayonnaise is a plastic liquid. 


\begin{tabular}{|c|c|c|c|c|c|c|c|c|c|c|c|c|c|c|c|c|c|c|}
\hline \multicolumn{19}{|l|}{ Measurement } \\
\hline \multirow[b]{2}{*}{ (A) Mastication behavior ${ }^{\mathrm{a}}$} & \multicolumn{3}{|c|}{ Carrier } & \multicolumn{3}{|c|}{ Topping } & \multicolumn{9}{|c|}{ Carrier:Topping } & & & \\
\hline & $\mathbf{F}$ & $\mathbf{p}$ & & $\mathbf{F}$ & p & & & & & $\mathbf{F}$ & p & & & & & & & \\
\hline Total mastication time (s) & 638.4 & $<0.001$ & $* * *$ & 44.0 & $<0.001$ & $* * *$ & & & & 4.0 & 0.008 & $* *$ & & & & & & \\
\hline Number of chews until swallowing & 584.9 & $<0.001$ & $* * *$ & 26.9 & $<0.001$ & $* * *$ & & & & 3.6 & 0.013 & $*$ & & & & & & \\
\hline Chewing frequency (chews/s) & 10.9 & 0.001 & $* *$ & 2.9 & 0.034 & * & & & & 0.1 & 0.981 & NS & & & & & & \\
\hline Maximum vertical jaw movement (mm) & 16.3 & $<0.001$ & $* * *$ & 7.8 & $<0.001$ & $* * *$ & & & & 1.7 & 0.158 & NS & & & & & & \\
\hline \multirow[t]{2}{*}{ Maximum lateral jaw movement $(\mathrm{mm})$} & 12.7 & $<0.001$ & $* * *$ & 3.8 & 0.011 & * & & & & 0.2 & 0.906 & NS & & & & & & \\
\hline & \multicolumn{3}{|c|}{ Carrier } & \multicolumn{3}{|c|}{ Topping } & \multicolumn{3}{|c|}{ Time } & \multicolumn{3}{|c|}{ Carrier:Topping } & \multicolumn{3}{|c|}{ Carrier:Time } & \multicolumn{3}{|c|}{ Topping:Time } \\
\hline (B) Bolus properties ${ }^{\mathrm{b}}$ & $\mathbf{F}$ & $\mathbf{p}$ & & $\mathbf{F}$ & p & & $\mathbf{F}$ & $\mathbf{p}$ & & $\mathbf{F}$ & $\mathbf{p}$ & & $\mathbf{F}$ & p & & $\mathbf{F}$ & p & \\
\hline Moisture content (wt\%) & 237.0 & $<0.001$ & $* * *$ & 41.3 & $<0.001$ & $* * *$ & 190.2 & $<0.001$ & $* * *$ & 0.2 & 0.9 & NS & 17.1 & $<0.001$ & $* * *$ & 2.3 & 0.033 & $*$ \\
\hline Saliva content (g/g dry weight) & 173.9 & $<0.001$ & $* * *$ & 54.6 & $<0.001$ & $* * *$ & 163.2 & $<0.001$ & $* * *$ & 3.1 & 0.026 & $*$ & 7.4 & $<0.001$ & $* * *$ & 2.0 & 0.072 & NS \\
\hline Rate of saliva incorporation ( $\mathrm{g} / \mathrm{min})$ & 92.3 & $<0.001$ & $* * *$ & 4.3 & 0.006 & $* *$ & 15.8 & $<0.001$ & $* * *$ & 5.2 & 0.002 & $* *$ & 1.5 & 0.228 & NS & 2.5 & 0.024 & $*$ \\
\hline Peak force $(\mathrm{N})$ & 55.7 & $<0.001$ & $* * *$ & 124.3 & $<0.001$ & $* * *$ & 123.6 & $<0.001$ & $* * *$ & 4.6 & 0.004 & $* *$ & 2.9 & 0.058 & NS & 1.1 & 0.336 & NS \\
\hline Adhesiveness $(\mathrm{g} \cdot \mathrm{s})$ & 99.0 & $<0.001$ & $* * *$ & 51.0 & $<0.001$ & $* * *$ & 108.6 & $<0.001$ & $* * *$ & 21.7 & $<0.001$ & $* * *$ & 54.8 & $<0.001$ & $* * *$ & 6.9 & $<0.001$ & $* * *$ \\
\hline \multirow[t]{2}{*}{ Cohesiveness } & 298.5 & $<0.001$ & $* * *$ & 8.9 & $<0.001$ & $* * *$ & 3.5 & 0.03 & $*$ & 6.4 & $<0.001$ & $* * *$ & 0.3 & 0.749 & NS & 2.2 & 0.037 & $*$ \\
\hline & \multicolumn{3}{|c|}{ Carrier } & \multicolumn{3}{|c|}{ Topping } & \multicolumn{3}{|c|}{ Time } & \multicolumn{3}{|c|}{ Carrier:Topping } & \multicolumn{3}{|c|}{ Carrier:Time } & \multicolumn{3}{|c|}{ Topping:Time } \\
\hline (C) Sensory characteristics ${ }^{\mathbf{b}}$ & $\mathbf{F}$ & p & & $\mathbf{F}$ & p & & $\mathbf{F}$ & $\mathbf{p}$ & & $\mathbf{F}$ & p & & $\mathbf{F}$ & $\mathbf{p}$ & & $\mathbf{F}$ & p & \\
\hline Dryness & 651.5 & $<0.001$ & $* * *$ & 115.3 & $<0.001$ & $* * *$ & 154.9 & $<0.001$ & $* * *$ & 0.2 & 0.925 & NS & 15.0 & $<0.001$ & $* * *$ & 1.9 & 0.054 & NS \\
\hline Firmness & 245.7 & $<0.001$ & $* * *$ & 11.1 & $<0.001$ & $* * *$ & 160.6 & $<0.001$ & $* * *$ & 0.1 & 0.978 & NS & 30.9 & $<0.001$ & $* * *$ & 1.4 & 0.174 & NS \\
\hline Stickiness & 21.4 & $<0.001$ & $* * *$ & 3.7 & 0.011 & $*$ & 54.4 & $<0.001$ & $* * *$ & 0.8 & 0.472 & NS & 3.4 & 0.017 & $*$ & 3.5 & $<0.001$ & $* * *$ \\
\hline Flavor intensity & 30.2 & $<0.001$ & $* * *$ & 328.5 & $<0.001$ & $* * *$ & 75.0 & $<0.001$ & $* * *$ & 3.6 & 0.013 & $*$ & 2.0 & 0.107 & NS & 6.1 & $<0.001$ & $* * *$ \\
\hline
\end{tabular}




\begin{tabular}{|c|c|c|c|c|c|c|c|c|}
\hline \multirow[b]{2}{*}{ (A) Bolus properties } & \multicolumn{3}{|c|}{ Carrier } & \multicolumn{3}{|c|}{ Topping } & \multicolumn{2}{|c|}{ Carrier:Topping } \\
\hline & $\mathbf{F}$ & $\mathbf{p}$ & & $\mathbf{F}$ & $\mathbf{p}$ & & $\mathbf{F}$ & $\mathbf{p}$ \\
\hline Moisture content (wt\%) & 55.2 & $<0.001$ & $* * *$ & 21.1 & $<0.001$ & **** & 0.2 & $0.865 \mathrm{NS}$ \\
\hline Saliva content (g/g dry weight) & 96.4 & $<0.001$ & $* * *$ & 29.0 & $<0.001$ & $* * *$ & 1.4 & $0.258 \mathrm{NS}$ \\
\hline Rate of saliva incorporation $(\mathrm{g} / \mathrm{min})$ & 45.7 & $<0.001$ & **** & 5.0 & 0.003 & ** & 2.6 & $0.057 \mathrm{NS}$ \\
\hline Peak force $(\mathrm{N})$ & 32.6 & $<0.001$ & **** & 76.0 & $<0.001$ & *** & 0.6 & $0.634 \mathrm{NS}$ \\
\hline Adhesiveness $(\mathrm{g} \cdot \mathrm{s})$ & 0.0 & 0.835 & NS & 27.7 & $<0.001$ & $* * *$ & 3.8 & $0.010 *$ \\
\hline \multirow[t]{2}{*}{ Cohesiveness } & 134.8 & $<0.001$ & $* * *$ & 12.5 & $<0.001$ & $* * *$ & 1.9 & $0.125 \quad \mathrm{NS}$ \\
\hline & \multicolumn{3}{|c|}{ Carrier } & \multicolumn{3}{|c|}{ Topping } & \multicolumn{2}{|c|}{ Carrier:Topping } \\
\hline (B) Sensory characteristics & $\mathbf{F}$ & $\mathbf{p}$ & & $\mathbf{F}$ & p & & $\mathbf{F}$ & $\mathbf{p}$ \\
\hline Dryness & 52.1 & $<0.001$ & **** & 25.3 & $<0.001$ & *** & 1.4 & $0.242 \mathrm{NS}$ \\
\hline Firmness & 1.9 & 0.166 & NS & 10.2 & $<0.001$ & **** & 0.9 & $0.419 \mathrm{NS}$ \\
\hline Stickiness & 0.4 & 0.553 & NS & 4.6 & 0.004 & ** & 0.8 & $0.508 \mathrm{NS}$ \\
\hline Flavor intensity & 14.9 & $<0.001$ & *** & 87.3 & $<0.001$ & **** & 1.7 & $0.174 \mathrm{NS}$ \\
\hline
\end{tabular}

\begin{tabular}{|c|c|c|c|c|c|c|c|c|c|c|c|c|c|}
\hline \multirow{3}{*}{$\frac{\text { (A) Bolus properties }}{\text { Moisture content (wt } \%)}$} & \multicolumn{7}{|c|}{ Bread $($ mean \pm SE) } & \multicolumn{6}{|c|}{ Crackers $($ mean \pm SE) } \\
\hline & without topping & \multicolumn{2}{|c|}{ firm cheese } & \multicolumn{2}{|c|}{ cheese spread } & \multicolumn{2}{|l|}{ mayonnaise } & without topping & \multicolumn{2}{|c|}{ firm cheese } & \multicolumn{2}{|l|}{ cheese spread } & mayonnaise \\
\hline & $55.0 \pm 1.5 \mathrm{~b}$ & $52.3 \pm 0.9$ & - & $55.1 \pm 1.2$ & $\mathrm{~b}$ & $57.9 \pm 1.1$ & & $50.4 \pm 1.9$ b & $48.1 \pm 1.2$ & & $51.2 \pm 1.4 \mathrm{~b}$ & & $54.3 \pm 1.5$ \\
\hline Saliva conte & $8 \pm 0.06$ a & $0 \pm 0.04$ & $\mathrm{~b}$ & $2 \pm 0.07$ & $\mathrm{~b}$ & $46 \pm 0.08$ & $\mathrm{~b}$ & $0.97 \pm 0.06 \mathrm{a}$ & $.66 \pm 0.05$ & $\mathrm{~b}$ & $66 \pm 0.07 b$ & b & 0.74 \\
\hline Rate & $4.5 \pm 0.5$ & $5.6 \pm 0.4$ & $a b$ & $4.2 \pm 0.7$ & b & $5.1 \pm 1.6$ & $\mathrm{a}$ & $6.1 \pm 0.6 \quad b$ & $6.2 \pm 0.4$ & 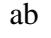 & $5.9 \pm 0.6$ & b & $7.6 \pm 0.8 \quad a$ \\
\hline Peak f & $0.49 \pm 0.05 \mathrm{~b}$ & $0.53 \pm 0.03$ & a & $0.49 \pm 0.04$ & $a b$ & $0.19 \pm 0.01$ & $\mathrm{c}$ & $0.67 \pm 0.08 \mathrm{~b}$ & $0.69 \pm 0.05$ & $\mathrm{a}$ & $0.67 \pm 0.06 \mathrm{a}$ & $\mathrm{ab}$ & $0.29 \pm 0.03$ \\
\hline & $2 \pm 2$ & $-26 \pm 3$ & $\mathrm{ab}$ & $-30 \pm 3$ & a & $-8 \pm 1$ & $\mathrm{c}$ & $-19 \pm 2$ & $-25 \pm 3$ & a & $-32 \pm 4$ & & $-15 \pm 3$ \\
\hline \multirow[t]{2}{*}{ Cohesiveness } & $6 \pm 0.01 \mathrm{c}$ & $.52 \pm 0.01$ & $\mathrm{~b}$ & $0.53 \pm 0.01$ & $\mathrm{ab}$ & $.52 \pm 0.01$ & $\mathrm{a}$ & $0.38 \pm 0.01 \mathrm{c}$ & $0.39 \pm 0.02$ & D & $0.41 \pm 0.02 \mathrm{a}$ & $\mathrm{ab}$ & $0.45 \pm 0.02$ \\
\hline & \multicolumn{7}{|c|}{ Bread $($ mean \pm SE) } & \multicolumn{6}{|c|}{ Crackers $(\operatorname{mean} \pm \mathrm{SE})$} \\
\hline (B) $\mathrm{S}$ & ithout topping & firm cheese & & cheese sprea & & mayol & & without topping & firm cheese & & cheese spread & & mayonnaise \\
\hline Dryne: & $5.3 \pm 3.2$ & $36.6 \pm 3.0$ & $\mathrm{~b}$ & $28.4 \pm 2.8$ & $\mathrm{c}$ & $29.0 \pm 3.3$ & & $62.3 \pm 4.2$ & $48.5 \pm 3.8$ & $\mathrm{~b}$ & $44.6 \pm 3.5 \mathrm{c}$ & & $36.7 \pm 3.3$ \\
\hline & $2 \pm 2.6 \quad a b$ & $51.3 \pm 3.4$ & $\mathrm{a}$ & $5 \pm 2.9$ & $\mathrm{~b}$ & $36.7 \pm 3.0$ & 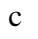 & $51.5 \pm 2.7$ & $50.3 \pm 2.7$ & a & $5.6 \pm 3.2 \quad b$ & b & $41.2 \pm 3.5$ \\
\hline Sticki & $58.8 \pm 2.7 \quad \mathrm{a}$ & $62.2 \pm 3.1$ & $\mathrm{a}$ & $56.9 \pm 3.6$ & $\mathrm{a}$ & $48.7 \pm 3.8$ & $\mathrm{~b}$ & $59.9 \pm 3.5$ & $59.3 \pm 3.5$ & $\mathrm{a}$ & $57.8 \pm 3.6 \quad \mathrm{a}$ & $\mathrm{a}$ & $54.1 \pm 3.7 \quad b$ \\
\hline Flavor intensity & $26.7 \pm 2.9 c$ & $56.8 \pm 3.3$ & $\mathrm{~b}$ & $55.6 \pm 2.8$ & $\mathrm{~b}$ & $68.9 \pm 2.8$ & $\mathrm{a}$ & $26.0 \pm 3.1 \quad c$ & $50.4 \pm 2.7$ & 0 & $44.2 \pm 3.4$ & b & $60.9 \pm 2.7$ \\
\hline
\end{tabular}

F-values and $\mathrm{p}$-values are derived from linear mixed models with carrier, topping and the interaction as fixed effect, and subjects and replicates as random effects.

793 Significance is presented as NS (non-significant); * $(\mathrm{p}<0.05), * *(\mathrm{p}<0.01)$, and $* * *(\mathrm{p}<0.001)$.

794 Different letters indicate significant differences between bread samples or cracker samples $(\mathrm{p}<0.05)$ 